Orlando R. Hung MD, *

Gregory M.T. Hare MD PhD, *

Susan Brien MD†

\title{
Head elevation reduces head-rotation associated increased ICP in patients with intracranial tumours
}

Purpose: To quantify the effects of graded head rotation and elevation on intracranial pressure (ICP) in neurosurgical patients, before and after induction of general anesthesia.

Methods: Patients with supratentorial tumours $(n=12)$, scheduled for craniotomy with planned ICP monitoring, underwent baseline ICP measurements awake and supine ( $0^{\circ}$ rotation and elevation). Incremental degrees of head rotation $\left(15^{\circ}\right)$ and of head elevation $\left(10^{\circ}\right)$ were performed independently and in combination. Paired measurements of ICP at all levels of head rotation and elevation were also performed before and after induction of general anesthesia $(n=6)$.

Results: The baseline ICP was I2.3 $\pm 6.4 \mathrm{mmHg}(n=12)$. Changes of ICP were proportional to the degree of head rotation or elevation. Head rotation of $60^{\circ}$ maximally increased ICP to $24.8 \pm 14.3 \mathrm{mmHg}(P<0.05)$. Head elevation above $20^{\circ}$ reduced ICP, with a maximal reduction to $-0.2 \pm 5.5 \mathrm{mmHg}$ at $40^{\circ}$ elevation $(P<0.0 \mathrm{I})$. Head elevation to $30^{\circ}$ reduced the intracranial hypertension associated with head rotation. No differences were observed between ICP measurements made before or after induction of general anesthesia $(n=6)$. Three patients experienced headache with extreme head rotation $\left(<60^{\circ}\right)$ and intracranial hypertension (ICP $>20 \mathrm{mmHg}$ ).

Conclusion: Head rotation of $60^{\circ}$ caused an increase in ICP. Concomitant head elevation to $30^{\circ}$ reduced the intracranial hypertension associated with head rotation. Headache with head rotation may provide a useful clinical warning of elevated ICP.

Objectif : Quantifier les effets de la rotation et de l'élévation graduées de la tête sur la tension intracrânienne (TIC) chez des patients de neurochirurgie, avant et après l'induction de l'anesthésie générale.

Méthode : Des patients atteints de tumeurs sus-tentorielles $(n=12)$ devaient subir une craniotomie sous monitorage planifié de la TIC. On a mesuré les valeurs de base de la TIC à l'état d'éveil et en position couchée sur le dos $\left(0^{\circ}\right.$ de rotation et d'élévation). Des changements incrémentiels du degré de rotation ( $\left.15^{\circ}\right)$ et d'élévation de la tête $\left(10^{\circ}\right)$ ont été réalisés, indépendants les uns des autres et combinés. Les mesures appariées de TIC pour tous les degrés de rotation et d'élévation de la tête ont aussi été faites avant et après l'induction de l'anesthésie générale $(n=6)$.

Résultats : La TIC de base était de 12,3 $\pm 6,4 \mathrm{mmHg}(n=12)$. Les changements de TIC ont été proportionnels au degré de rotation et d'élévation de la tête. La rotation de $60^{\circ}$ a conduit à la TIC maximale de $24,8 \pm 14,3$ $\mathrm{mmHg}(P<0,05)$. L'élévation au-dessus de $20^{\circ}$ a réduit la TIC, la réduction maximale étant de $-0,2 \pm 5,5 \mathrm{mmHg}$ à $40^{\circ}$ d'élévation $(P<0,0 \mathrm{I})$. L'élévation de la tête à $30^{\circ}$ a réduit l'hypertension intracrânienne associée à la rotation de la tête. Aucune différence de TIC n'a été notée entre les mesures prises avant ou après l'induction de l'anesthésie générale $(n=6)$. Trois patients ont éprouvé des céphalées au moment de la rotation extrême de la tête $\left(<60^{\circ}\right)$ et une hypertension intracrânienne $(\mathrm{TIC})>20 \mathrm{mmHg}$.

Conclusion : La rotation de la tête de $60^{\circ}$ a causé une augmentation de la TIC. L'élévation concomitante de la tête à $30^{\circ}$ a réduit la $\mathrm{TIC}$ associée à la rotation de la tête. Les céphalées associées à la rotation de la tête peuvent servir d'indice clinique d'une TIC élevée.

From the Department of Anesthesia, Dalhousie University, ${ }^{*}$ Halifax, Nova Scotia, Canada and the Department of Neurosurgery, HotelDieu Grace Hospital, $†$ Windsor, Ontario, Canada. Address correspondence to: Dr. Orlando R. Hung, Department of Anesthesia, Queen Elizabeth II Health Sciences Centre, 1278 Tower Road, VG Site, Halifax, Nova Scotia, B3H 2Y9 Canada. Phone: 902-473-7767; Fax: 902-423-9454; E-mail hungorla@is.dal.ca This study was funded in part by a grant from Janssen Pharmaceutica Canada, Toronto, Ontario. Accepted for publication February 2, 2000. 
$\mathrm{E}$

LEVATION of intracranial pressure (ICP), or intracranial hypertension, occurs with increased volume of one or more of the three major intracranial components - brain parenchyma, blood volume or cerebral spinal fluid. ${ }^{1}$ Elevated ICP increases the risk of cerebral ischemia by reducing cerebral perfusion pressure (CPP) and may result in herniation of brain parenchyma. Space occupying lesions and cerebral edema secondary to trauma frequently result in an elevated ICP at the time of craniotomy. Head elevation lowers $\mathrm{ICP}^{2,3}$ and reduces intracranial hypertension secondary to trauma and intracranial hemorrhage in the ICU setting. ${ }^{4-9}$ Head rotation increases ICP by impeding venous drainage of the head in adults ${ }^{10,11}$ and infants. ${ }^{13}$ The increase in ICP associated with head rotation in infants was reduced by concomitant head elevation. ${ }^{13}$

Preoperative assessment of ICP in patients with intracranial tumours, prior to craniotomy, is important as these patients may have elevated baseline ICP with the risk of further exacerbations in intracranial hypertension during intraoperative positioning. Intraoperative head rotation and elevation are frequently used to position patients for craniotomy. However, no quantitative assessment of the relative changes in ICP with varying degrees of head rotation and elevation have been reported. A quantitative assessment of baseline ICP and the effect of independent and combined head rotation and elevation were undertaken to define the effect of intraoperative positioning on ICP.

Materials and methods

After obtaining institutional review board approval, informed consent was obtained from patients with supratentorial tumours scheduled for elective craniotomy. Patients were selected from a group already participating in a study requiring placement of a fibreoptic intracranial pressure monitor preoperatively in the Neurosurgical Intensive Care Unit. Patients with neurological deficits, an unstable cervical spine, confusion or intracranial hypertension requiring preoperative therapy (mannitol, furosemide or mechanical hyperventilation) were excluded from the study.

All procedures were performed in the Neurosurgical Intensive Care Unit prior to transportation to the operating room. Intravenous access was established using a \#16 gauge Jelco iv Catheter (Johnson \& Johnson Medical Inc., Arlington, TX). Arterial blood pressure monitoring was achieved using a \#20 gauge radial arterial catheter (Arrow International Inc., Reading, PA). Central venous pressures were assessed using a catheter (Polyurethane Drum-Cartridge ${ }^{\circledR}$ catheter, Abbott Ireland, Sligo, Ireland) threaded from the basilic vein into the subclavian vein. A fibreoptic intracranial pressure catheter (OLM 110-4B, Camino Laboratories, San Diego, CA) was calibrated prior to insertion. ${ }^{13}$ The catheter and bolt were inserted by the neurosurgical staff under local anesthesia, in the Neurosurgical Intensive Care Unit. Following the procedure, the patient was allowed to rest for a minimum of five hours prior to the study. No sedatives were administered before and during the study. Intracranial pressures were reported in $\mathrm{mmHg}$.

The baseline ICP was determined in the Intensive care Unit with the patients lying supine $\left(0^{\circ}\right.$ head elevation $)$ and the head in a neutral position $\left(0^{\circ}\right.$ rotation). The baseline ICP was recorded for five minutes prior to changing the head position. To investigate the effects of head rotation and elevation on ICP, four sets of measurements were made:

1. Head Rotation: While lying supine $\left(0^{\circ}\right.$ head elevation), the patient's head was turned, at the neck, to the side contralateral to the tumour in $15^{\circ}$ increments through a range of $0^{\circ}$ to $75^{\circ}$ utilizing a protractor (Magnetic Polycast ${ }^{\circledR}$ Protractor, Empire Level Manufacturing Corp., Milwaukee, WI). After each $15^{\circ}$ turn, the ICP equilibrated rapidly achieving a new stable pressure. The ICP was recorded after the pressure had stabilized for $30 \mathrm{sec}$.

2. Head Elevation: With the head in neutral rotation $\left(0^{\circ}\right.$ rotation $)$, the head of the bed was either low ered or elevated by extension or flexion at the hips, in $10^{\circ}$ increments, from $-10^{\circ}$ to $40^{\circ}$ utilizing a protractor (Magnetic Polycast ${ }^{\circledR}$ Protractor, Empire Level Manufacturing Corp., Milwaukee, WI). For each level of head elevation the ICP was recorded after the pressure had stabilized for $30 \mathrm{sec}$.

3. Head Rotation and Elevation: The head rotation maneuvre (Step \#1) was repeated with $30^{\circ}$ of head elevation.

4. General Anesthesia: In six of the 12 patients, steps 1 and 2 were repeated under general anesthesia. Following induction of anesthesia using $50 \mu \mathrm{g} \cdot \mathrm{kg}^{-1}$ alfentanil, $2.5 \mathrm{mg} \cdot \mathrm{kg}^{-1}$ thiopental, $0.15 \mathrm{mg} \cdot \mathrm{kg}^{-1}$ of pancuronium, maintenance anesthesia was provided using nitrous oxide $60 \%$ in oxygen and isoflurane 0.5 $\% \mathrm{ET}$, and $15 \mu \mathrm{g} \cdot \mathrm{kg}^{-1} \cdot \mathrm{min}^{-1}$ alfentanil. Under stable conditions with normal hemodynamics and $\mathrm{P}_{\mathrm{ET}} \mathrm{CO}_{2}$ at $30 \mathrm{mmHg}$ and with no surgical stimulation, measurements of ICP (Steps \#1 and 2) were repeated.

During the study, the arterial and central venous pressures were measured and recorded with pressure transducers adjusted to the level of the right atrium. For all procedures, the experiment was discontinued if the patient experienced discomfort or if the ICP increased to dangerous levels ( $>60 \mathrm{mmHg}$ ). 
Data were expressed as mean \pm SD. All continuous data were analyzed using ANOVA with repeated measures and post hoc multiple comparison test (Bonferroni correction). Correlation between ICP measurements during head rotation and elevation with patients awake and under general anesthesia was performed using linear regression analysis. Statistical significance was achieved at $P<0.05$.

\section{Results}

Patient demographics are shown in the Table. No changes in central venous pressure or arterial blood pressure were observed during measurements of ICP throughout the study. Transient headaches, with extreme head rotation, in three patients, were the only complication that occurred during the study.

Head rotation, with patients supine $\left(0^{\circ}\right.$ head elevation), resulted in a progressive increase in ICP from a baseline of $12.3 \pm 6.4 \mathrm{mmHg}$ to a maximum of $24.8 \pm$ $14.3 \mathrm{mmHg}$ at $60^{\circ}$ of rotation (Figure $1, P<0.05$ ). Changes in ICP correlated directly with the degree of head rotation $(\mathrm{r}=0.9594, \mathrm{n}=12, P<0.01)$. There was variability in the ICP measurement between the study patients. In particular, three patients had a baseline ICP above $20 \mathrm{mmHg}$ (Figure 1). In two of these patients there were notably larger increases in ICP with each $15^{\circ}$ of head rotation, accounting for the large standard deviations. In individuals with a baseline ICP below $20 \mathrm{mmHg}(\mathrm{n}=9)$, there was a gradual increase in ICP with progressive head rotation (Figure 1).

TAB LE Demographics and tumour types in patients undergoing intracranial pressure monitoring prior to craniotomy.

\begin{tabular}{lllll}
\hline Sex & $\begin{array}{c}\text { Age } \\
(y r)\end{array}$ & Weight $(\mathrm{kg})$ & $\begin{array}{l}\text { Tumour } \\
\text { Diameter }(\mathrm{cm})\end{array}$ & Tumour Type \\
\hline Male & 51 & 81 & 2.8 & Metastatic carcinoma \\
Male & 62 & 77 & 5.0 & Glioblastoma \\
Female & 58 & 66 & 3.0 & Metastatic carcinoma \\
Male & 55 & 72 & 3.0 & Astrocytoma \\
Female & 60 & 68 & 3.4 & Metastatic carcinoma \\
Male & 52 & 83 & 2.5 & Metastatic carcinoma \\
Female & 36 & 68 & 2.9 & Metastatic carcinoma \\
Female & 68 & 54 & 5.5 & Multiple glioblastoma \\
Female & 36 & 71 & 3.0 & Meningioma \\
Male & 49 & 102 & 2.8 & Glioblastoma \\
Male & 54 & 82 & 5.0 & Meningioma \\
Female & 46 & 77 & 2.5 & Glioblastoma \\
Male & & & & Metastatic $(\mathrm{n}=5)$ \\
$(\mathrm{n}=6)$ & & & & Glioblastoma $(\mathrm{n}=4)$ \\
Female & & & & Meningioma $(\mathrm{n}=2)$ \\
$(\mathrm{n}=6)$ & & & & Astrocytoma $(\mathrm{n}=1)$ \\
& & & & \\
& & & &
\end{tabular}

Mean \pm SD $52 \pm 975 \pm 12 \quad 3.5 \pm 1.1$

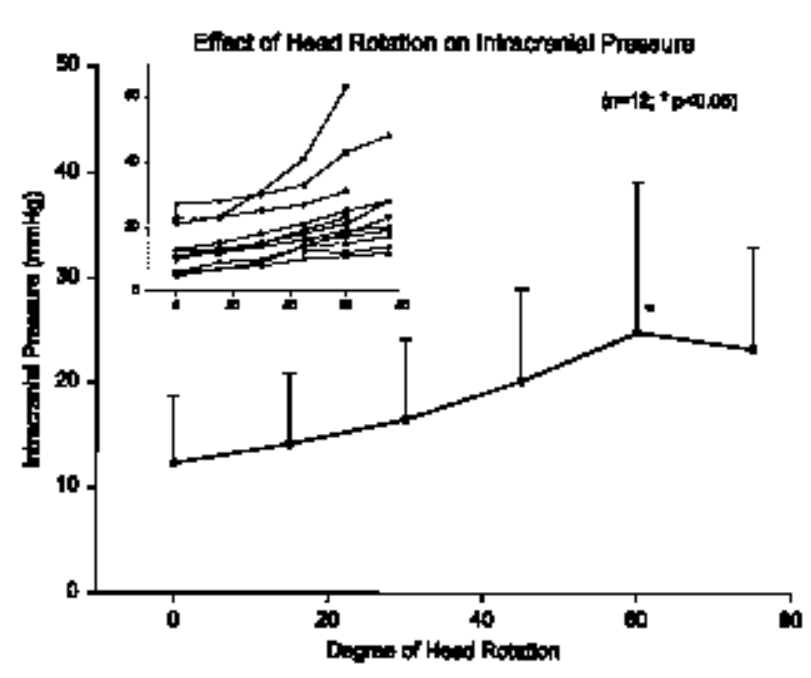

FIGURE 1 Intracranial pressure (ICP) measurements (mean \pm SD) associated with head rotation in awake patients with intracranial mass lesions. Head rotation caused a gradual increase in ICP reaching statistical significance at $60^{\circ}(P<0.05)$. The inset shows the ICP measurements associated with head rotation for each individual patient. Two patients with elevated baseline ICP demonstrated a more dramatic increase in ICP with incremental increases in head rotation resulting in a large standard deviation.

Head elevation, without any head rotation, resulted in progressive reduction in ICP (Figure 2). Changes in ICP correlated inversely with the degree of head elevation $(\mathrm{r}=-0.9848, \mathrm{n}=12, P<0.01)$. Head depression to $-10^{\circ}$ tended to increase the ICP from baseline. Head elevation, above the supine position $(12.3 \pm 6.4 \mathrm{mmHg})$, resulted in a progressive reduction in ICP reaching statistical significance by $20^{\circ}(5.0$ $\pm 5.9 \mathrm{mmHg}$ ) and a minimum of $-0.2 \pm 5.5 \mathrm{mmHg}$ by $40^{\circ}$ of head elevation (Figure $2, P<0.01$, relative to baseline). The three patients with high baseline ICP showed a proportional drop in ICP when compared to the individuals with lower baseline ICP (Figure 2).

Combination of head rotation with head elevation of $30^{\circ}$ resulted in ICP levels that were lower than those measured with patients supine $\left(0^{\circ}\right.$ head elevation) at all degrees of rotation (Figure $3, \mathrm{P}<0.05$, all comparisons). At $30^{\circ}$ of head elevation, the maximum mean ICP $\left(13.0 \pm 4.1 \mathrm{mmHg}\right.$ at $75^{\circ}$ head rotation $)$ approximated the baseline mean ICP $(12.3+6.4$ $\mathrm{mmHg})$ observed in supine patients $\left(0^{\circ}\right.$ head elevation) with no head rotation (Figure 3 ).

There was a good correlation $(\mathrm{r}=0.864, P<$ 0.001 ) between all ICP measurements performed before and after general anesthesia. There were no dif- 


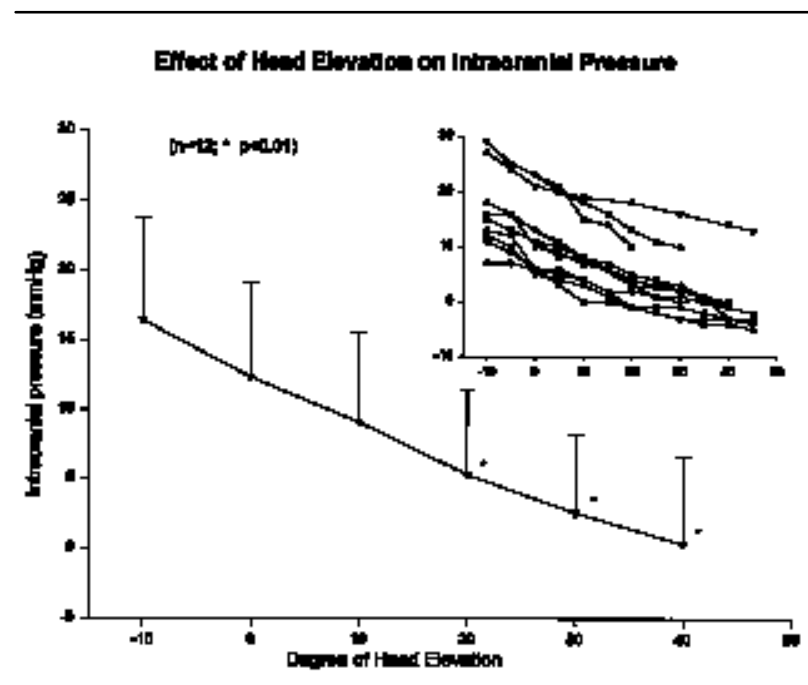

FIGURE 2 Intracranial pressure (ICP) measurements (mean \pm SD) associated with head elevation in awake patients with intracranial mass lesions. Head elevation caused a progressive reduction in ICP reaching statistical significance at $20^{\circ}$ elevation $\left(P<0.01,20^{\circ}\right.$ vs $0^{\circ}$ elevation). The inset shows the ICP measurements associated with head elevation for each individual patient. All individuals experienced a progressive decrease in ICP with head elevation.

ferences in ICP measurements during head rotation or elevation before or after general anesthesia (Figure 4).

Two of the three patients with an elevated baseline ICP experienced headache at $60^{\circ}$ of rotation $\left(0^{\circ}\right.$ head elevation) with ICP measurements of 22 and 62 $\mathrm{mmHg}$. One patient with a normal baseline ICP experienced headache at $75^{\circ}$ of rotation $\left(0^{\circ}\right.$ head elevation) with an ICP of $28 \mathrm{mmHg}$. In all cases, head rotation was stopped, the headache resolved, and no detrimental effects were noted.

\section{Discussion}

Although head rotation is known to increase $\mathrm{ICP}^{10,11}$ and head elevation is known to decrease ICP, ${ }^{2-9}$ the independent and combined effect of graded head rotation and elevation on ICP in preoperative neurosurgical patients has not been previously quantified. Determination of the relative importance of these two opposing maneuvres on ICP would assist in optimizing head position during craniotomy. As expected, a progressive increase in ICP was observed with head rotation in awake non-sedated patients scheduled for craniotomy. Head elevation alone caused a progressive reduction in ICP in all cases. In both cases, the effect on ICP was proportional to the degree of head rotation or elevation. Furthermore, head elevation to $30^{\circ}$

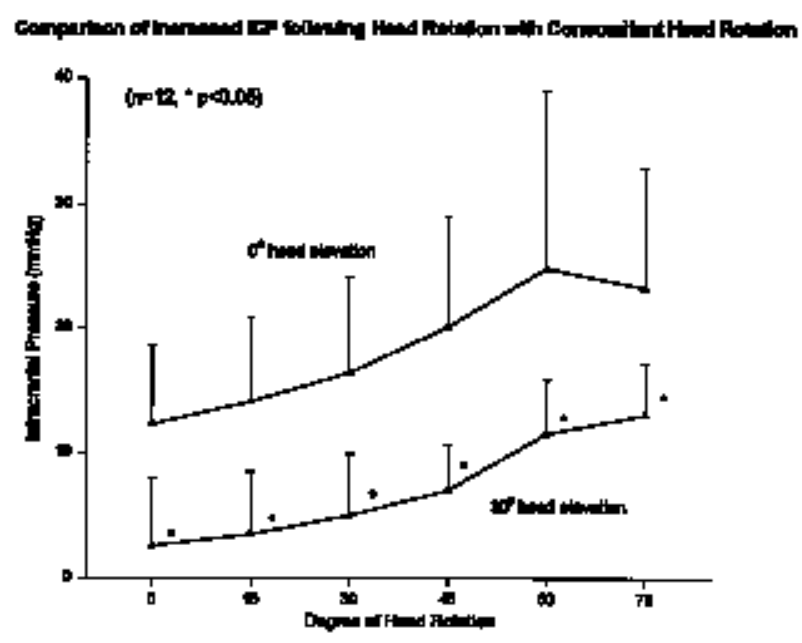

FIGURE 3 Intracranial pressure (ICP) measurements (mean \pm SD) associated with head rotation in awake patients with a $0^{\circ}$ head elevation (closed circle) and a $30^{\circ}$ head elevation (closed triangle). Head elevation to $30^{\circ}$ resulted in a reduced level of ICP at every degree of head rotation between $0^{\circ}$ and $75^{\circ}(P<0.05$ for each degree of rotation). The maximum ICP with head elevation of $30^{\circ}$ was similar to the baseline ICP in patients with $0^{\circ}$ head elevation.

attenuated the rise in ICP associated with head rotation alone. In the presence of $30^{\circ}$ head elevation, the mean ICP at $75^{\circ}$ rotation was similar to the baseline ICP $\left(0^{\circ}\right.$ head elevation and rotation $)$. This suggests that maintaining $30^{\circ}$ of head elevation would minimize the intracranial hypertension associated with head rotation. Goldberg et al. observed similar findings measuring fontanelle pressures in neonates. They demonstrated an increase in ICP with head rotation that was partially off-set by $30^{\circ}$ of head elevation. ${ }^{12}$ However, incremental degrees of head elevation and rotation were not measured in their study. ${ }^{12}$

Head rotation increases ICP by compressing the jugular veins, thereby reducing venous drainage of the head. ${ }^{10,11}$ Head elevation augments venous drainage of the head and reduces ICP in the ICU setting. ${ }^{4-9}$ Enhanced venous drainage induced by head elevation may off-set the effect of impaired venous drainage caused by head rotation resulting in a reduced risk for intracranial hypertension.

In the ICU, excessive head elevation greater than $30^{\circ}$ has been observed to decrease systemic arterial pressure, cardiac output, central venous pressure and cerebral perfusion pressure (CPP) suggesting that excessive head elevation may have detrimental effects on cerebral perfusion. ${ }^{4,6}$ Schneider $e t a l$. found that $30^{\circ}$ 

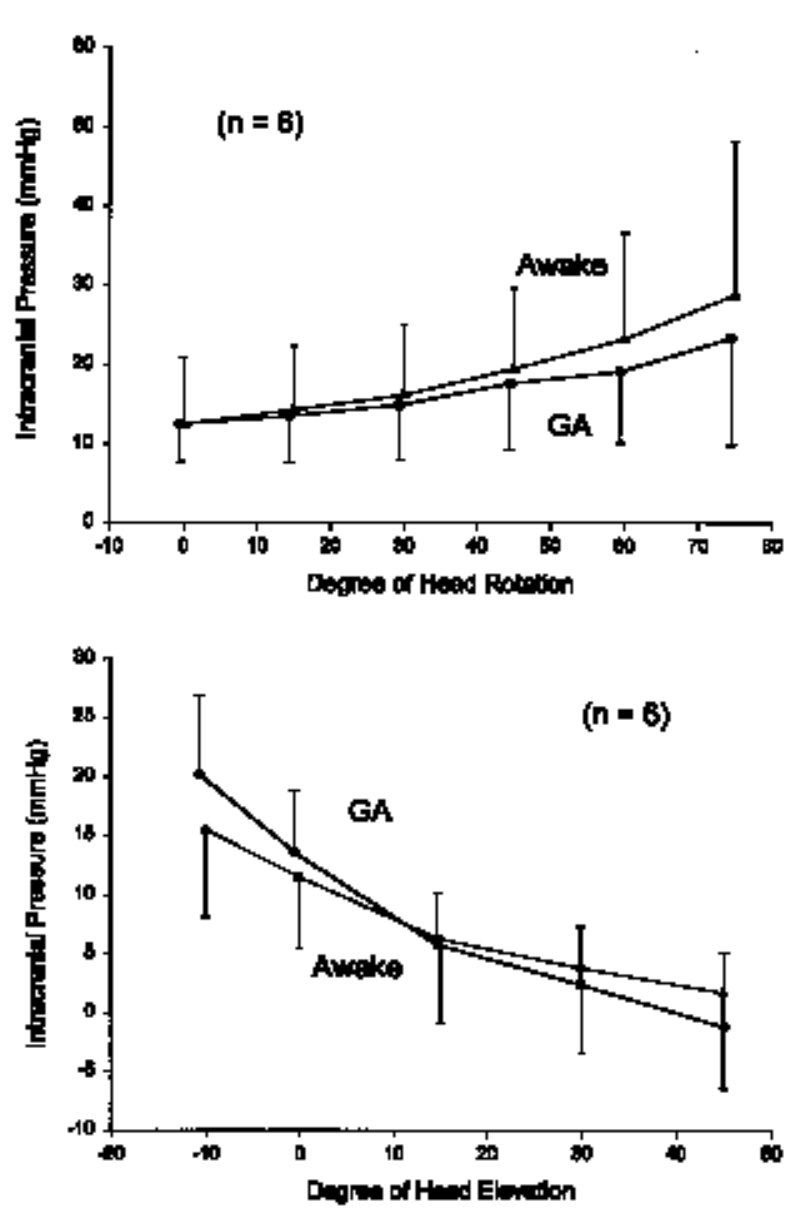

FIGURE 4 Intracranial pressure (ICP) measurements (mean \pm $\mathrm{SD}$ ) associated with head rotation (upper panel, $n=6$ ) and head elevation (lower panel, $n=6$ ) before (closed triangle) or after (closed circle) general anesthesia. There were no statistically significant differences in the ICP measurements associated with head rotation or elevation between the two groups at every head position.

of elevation provided $92 \%$ of the maximal reduction in ICP with no detrimental effect on CPP or jugular venous oxygen saturation. ${ }^{8}$ Meixensberger et al. demonstrated a reduction in ICP without any detrimental effect on brain tissue oxygen content with a head elevation of $30^{\circ} .^{9}$ In this study, $30^{\circ}$ of head elevation reduced intracranial hypertension induced by head rotation without evidence of any detrimental effect on blood pressure or central venous pressure. Indeed, no changes in central venous pressure or arterial blood pressure were observed for any of the head elevation and rotation maneuvres in this study.

Application of a rigid cervical collar has been associated with elevated ICP probably due to impaired venous drainage. ${ }^{14}$ Utilization of head elevation may aid venous drainage of the head when cervical collars are used. ${ }^{14}$

Due to time constraints imposed by the clinical requirements of the neurosurgeons, only six patients had repeated ICP measurements with head rotation and elevation under general anesthesia. Lack of any differences in ICP measured before and after the induction of general anesthesia suggests that preoperative assessment of ICP provides useful information of intraoperative ICP changes associated with head positioning under general anesthesia prior to surgical intervention.

Headache was observed in three patients undergoing extreme head rotation $\left(>60^{\circ}\right)$ and was associated with an elevated ICP $(>20 \mathrm{mmHg})$. Thus, headache with head rotation preoperatively may suggest the presence of an elevated baseline ICP, thereby identifying patients at risk for elevated ICP intraoperatively.

In summary, head rotation increased ICP while head elevation reduced ICP. In both cases, the effect on ICP was proportional to the degree of head rotation or elevation. In combination, head elevation counteracted the observed increase in ICP associated with head rotation. When positioning neurosurgical patients, head elevation up to $30^{\circ}$ may reduce increased ICP associated with head rotation without any detrimental hemodynamic effect. Extreme degrees of head rotation above $60^{\circ}$ may detrimentally increase ICP. During the preoperative anesthetic assessment, the presence of headache associated with head rotation should alert the anesthesiologist to the possibility of intracranial hypertension.

\section{References}

1 Lyons MK, Meyer FB. Cerebrospinal fluid physiology and the management of increased intracranial pressure. Mayo Clin Proc 1990; 65: 684-707.

2 Frank JI. Management of intracranial hypertension. Med Clin North Am 1993; 77: 61-76.

3 Simmons BJ. Management of intracranial hemodynamics in the adult: a research analysis of head positioning and recommendations for clinical practice and future research. J Neursci Nurs 1997; 29: 44-9.

4 Durward QJ, Amacher AL, Del Maestro RF, Sibbald $W J$. Cerebral and cardiovascular responses to changes in head elevation in patients with intracranial hypertension. J Neurosurg 1983; 59: 938-44.

5 Emery JR, Peabody JL. Head position affects intracranial pressure in newborn infants. J Pediatr 1983; 103: 950-3.

6 Rosner MJ, Coley IB. Cerebral perfusion pressure, intracranial pressure, and head elevation. J Neurosurg 1986; 65: 636-41. 
7 Feldman Z, Kanter MJ, Robertson CS, et al. Effect of head elevation on intracranial pressure, cerebral perfusion pressure, and cerebral blood flow in head-injured patients. J Neurosurg 1992; 76: 207-11.

8 Schneider G-H, v Helden A, Franke R, Lanksch WR, Unterberg $A$. Influence of body position on jugular venous oxygen saturation, intracranial pressure and cerebral perfusion pressure. Acta Neurochir 1993; 59(Suppl): 107-12.

9 Meixensberger J, Baunach S, Amschler J, Dings J, Roosen $K$. Influence of body position on tissue- $\mathrm{pO}_{2}$, cerebral perfusion pressure and intracranial pressure in patients with acute brain injury. Neurol Res 1997; 19: 249-53.

10 Lipe HP, Mitchell PH. Positioning the patient with intracranial hypertension: how turning and head rotation affect the internal jugular vein. Heart Lung 1980; 9: 1031-7.

11 Williams A, Coyne SM. Effects of neck position on intracranial pressure. Am J Crit Care 1993; 2: 68-71.

12 Goldberg RN, Joshi A, Moscoso P, Castillo T. The effect of head position on intracranial pressure in the neonate. Crit Care Med 1983; 11: 428-30.

13 Chambers IR, Kane PJ, Choksey MS, Mendelow AD. An evaluation of the Camino ventricular bolt system in clinical practice. Neurosurgery 1993; 33: 866-8.

14 Craig GR, Nielsen MS. Rigid cervical collars and intracranial pressure. Intensive Care Med 1991; 17: 504-5. 